\title{
GUEST ESSAY A lesson for botanic gardens from the Covid-19 pandemic: reaching wider audiences through online activity
}

\section{Beverley Glover ${ }^{1}$}

Beverley Glover is Director of Cambridge University Botanic Garden (CUBG) and Professor of Plant Systematics and Evolution at the University of Cambridge. Beverley is also a Trustee of Royal Botanic Garden Edinburgh (RBGE) and Chair of the RBGE Science Advisory Committee. Her research interests focus on the evolution and development of floral traits that attract animal pollinators. She has a BSc in Plant and Environmental Biology and a PhD in Plant Developmental Biology.

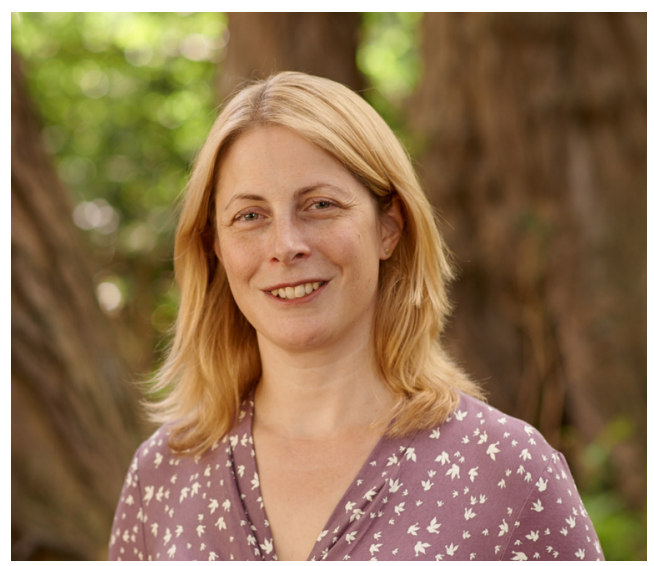

\section{Abstract}

The power of botanic gardens to connect people to plants has traditionally stemmed from the physical interaction between visitors and living collections. However, the Covid-19 pandemic forced many botanic gardens to consider alternative, online programmes of engagement. Here I argue that this experience has been revelatory, showing us that digital approaches provide the power not only to reach a wider audience, but to connect more deeply with that audience if the content is carefully designed. The new opportunities provided for connecting people to plants will be an important part of botanic garden engagement programmes in the years ahead.

\section{Botanic gardens connect people to plants, physically}

Botanic gardens are founded across the world for many different purposes, with their primary goals depending on their funding, their governance and their history. Some botanic gardens play significant roles in conservation and as repositories of germplasm, others in scientific and horticultural research, and others focus mainly on education and knowledge exchange. In practice, most botanic gardens would include some or all of these activities in their strategic goals, with the balance being determined by historic decision and current leadership (Chen \& Sun, 2018; Mounce et al., 2017). However, whatever the primary focus, all botanic gardens share a role in connecting people with plants in a simple, purely physical sense. For the majority

${ }^{1}$ Address: Department of Plant Sciences, University of Cambridge, Downing Street, Cambridge, CB2 3EA, UK. Email: bjg26@cam.ac.uk 
that are open to the public this connection is achieved apparently effortlessly (although in fact with considerable horticultural skill and artistry!). Living collections of plants are presented in ways that engage, delight and amaze visitors, encouraging an ever-growing number of people to explore botanic gardens (Association of Leading Visitor Attractions, n.d.). The physical connection between people and plants is encouraged in many botanic gardens, both explicitly and implicitly. Plantings designed for textural interest, or for scent, encourage visitors to touch, smell and rub foliage and flowers, and winter plantings are often focused around the textures of bark and the architecturally striking shapes of branch and leaf. More explicitly, many botanic gardens will use interpretation materials, including boards and trails, which encourage physical contact with plants to experience their scent or texture. Even interpretation which is focused on visual aspects of plants will often require visitors to look at a plant more closely, or in a different way, thereby deepening their sense of physical connection to the plant, and by extension to the living world around them. This physical connection is recognised as a vital part of the work that botanic gardens do, enhancing the wellbeing of visitors (Carrus et al., 2017) and contributing to an appreciation for and understanding of plants which, in turn, increases the plants' visibility and their perceived value in conservation programmes (Chen \& Sun, 2018).

Botanic gardens have often been slower than museums to adapt to an increasingly digital era. It can be argued that this has not been through inertia, but through a genuine commitment to the physical connection between plant and person. Studies of the strategies underpinning botanic garden interpretation programmes reveal that the conscious decision has often been made not to use digital approaches. In Cambridge University Botanic Garden (CUBG) we have debated the use of digital interpretation platforms repeatedly over the last decade, always concluding that we did not want to encourage visitors to look at their screens but at the plants in front of them. The importance of the physical connection, and the perceived need not to place a barrier between plant and person, has ironically acted as a barrier which has prevented a full exploration of the potential for digital engagement.

\section{A traumatic conversion to online engagement}

Like colleagues around the world, the events of 2020 and 2021 have forced us to re-evaluate the use of digital technologies in the ways that we connect plants and people. In March 2020, in the very week that the UK entered its first Covid-19 enforced national lockdown, the Yoshino cherry tree on our Main Lawn burst into flower. Prunus $\times$ yedoensis is a hybrid of unknown parents, with a low, spreading habit growing up to $15 \mathrm{~m}$ in height. It is grown widely as a street tree in Japan, primarily for its abundance of lightly scented, white to pale pink flowers, which are held in racemes of four or more, and which usually precede the foliage. Ours entered the living collection in 1997 and is truly spectacular (Fig. 1). The thought that we were about to close the botanic garden to visitors for an undefined number of weeks or months, and that nobody would see this glorious specimen, was too much to bear. We recorded a short film in which a member of staff walked around the cherry, talking quietly about the colour, shape and scent of the flowers. We filmed close up, and from a distance as you approach the tree. The whole film had a calm, measured feel to it, and 


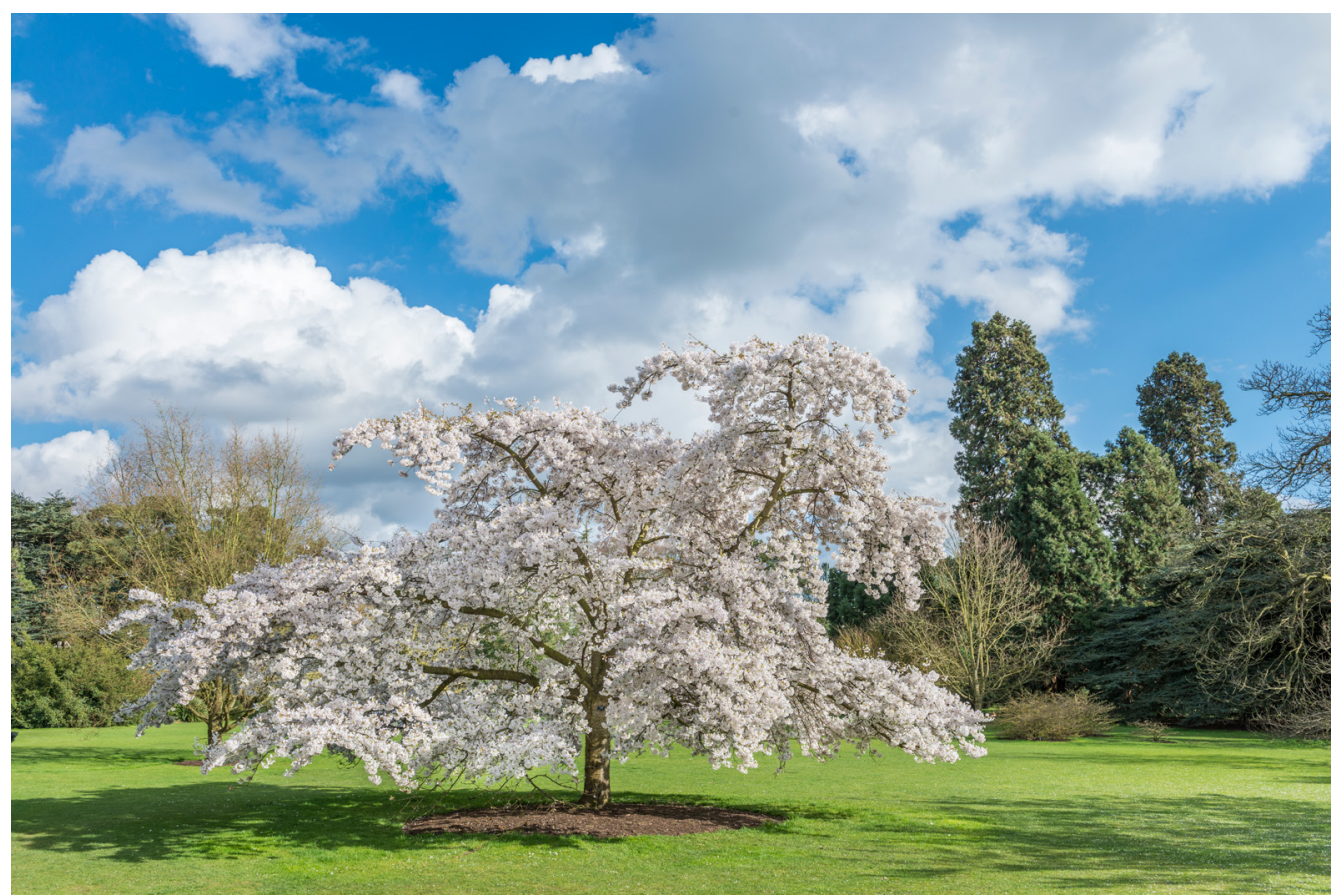

Fig. 1 Prunus $x$ yedoensis in flower on the Main Lawn at Cambridge University Botanic Garden. Photo: Howard Rice.

worked hard to give as good a connection as possible to the plant through this unusual medium. We called the film a 'Wellness Wander', and released it online, with no real idea whether it would be watched. In fact that first Wander has so far been watched over 20,000 times. The feedback was extraordinary, in terms of both the enthusiasm and the range of viewers. People loved the idea of a slow, intimate wander around a plant or a section of the garden, and they were vocal about the benefits to be had from focusing on nature for this brief spell. One viewer commented: 'Exactly what we need at the moment! Can't imagine anywhere l'd rather be. Thank you!'

But we were also astonished by the geographic spread of the viewers - comments came in from all over the world, such as 'Thank you. English spring is so welcome up here in still grey Minnesota', from people who would never have visited Cambridge in normal circumstances. We realised that this new means of connecting plants and people had a different sort of power from the purely physical connection we usually focus on. Through the first months of the pandemic we released our Wellness Wanders weekly, responding to the demand for a connection to the natural world. As things settled, and we were able to reopen the garden physically, we reduced the frequency but continued to produce the films. $^{2}$

The Wellness Wanders were the first of a new set of online initiatives that CUBG has developed over the last two years. As we became aware of the popularity of the films, we started to design new content, always focused on the connection between people and plant. Some of these were small - fun plant facts released on Twitter, or Bitesize

\footnotetext{
${ }^{2}$ The full set can be viewed at www.botanic.cam.ac.uk/ wellness-wander
} 


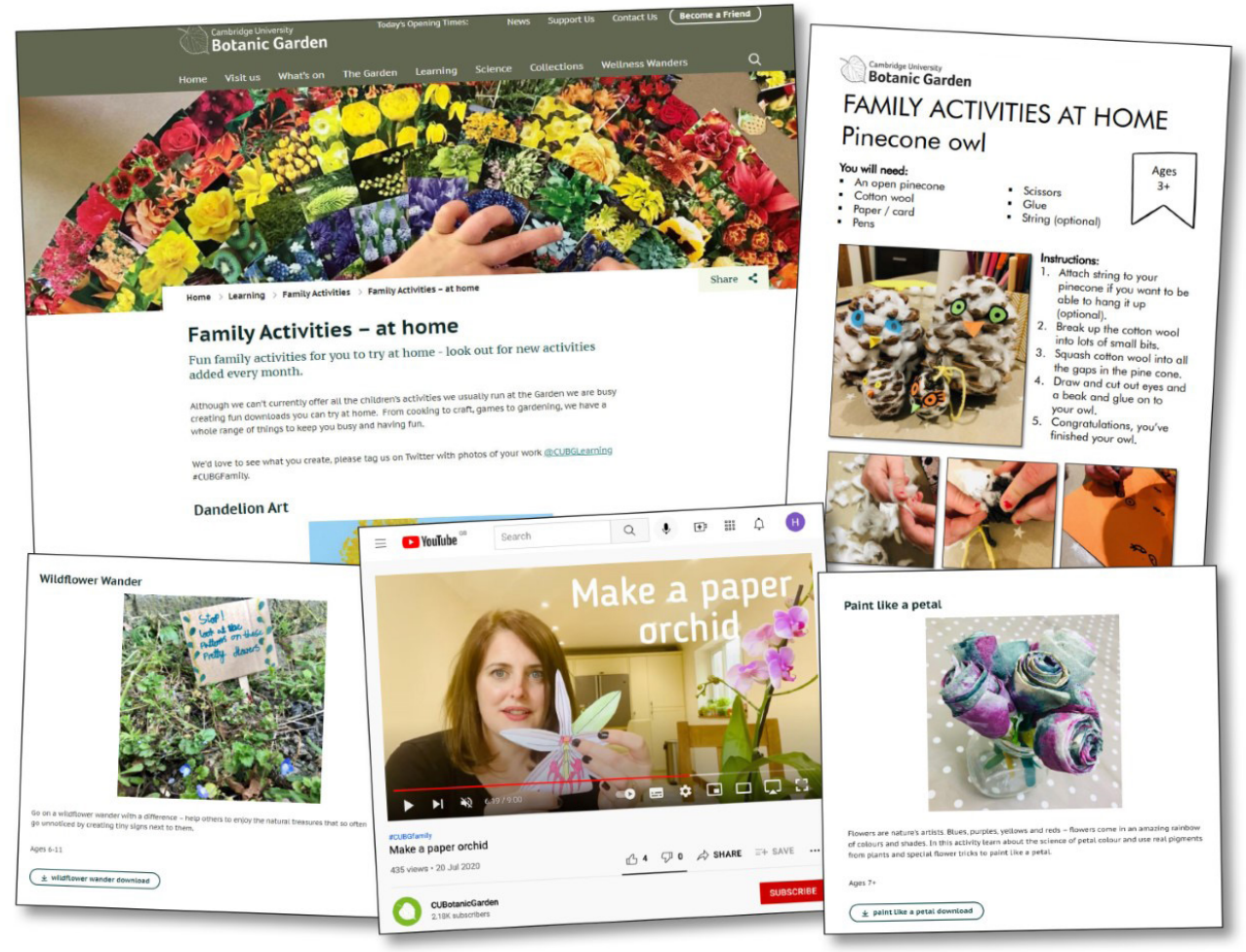

Fig. 2 Examples of online family activities created during the Covid-19 pandemic by CUBG's Learning Team. Image compiled by Hamish Symington.

Botanics films of only a few seconds with no voiceover - and some were more substantial. We established an online Gardening Club, recognising people's enthusiasm for working in their own gardens especially during the lockdowns. These films retained the measured, calm feel of the Wellness Wanders, but focused each week on different tasks involved in growing your own garden. We also produced regular 'at home' children's activities, which required connection back to nature. These ranged from craft activities with pine cones through wildflower bingo to an amazingly popular 'guerrilla labelling' activity with cardboard signs and lollipop sticks (Fig. 2). ${ }^{3}$

${ }^{3}$ The full set is available at www.botanic.cam.ac.uk/ education-learning/families/athome
All this online activity was established as a response to the enforced suspension of our normal in-person events, and for the first year or so of the pandemic we viewed it as a temporary state of affairs. However, the flowering of our Strophocactus wittii (one of the many species known colloquially as 'moonflower') in February 2021 forced us to think harder about the role we have in the world. S. wittii is found exclusively above the high waterline of the floodplain rainforests of the Amazon Basin. Its white, nocturnal flowers reach $27 \mathrm{~cm}$ in length and emit a beautiful sweet-smelling fragrance as they blossom at sunset, most likely attracting hawkmoth pollinators (Fig. 3). It is an unusual cactus, growing epiphytically with pads (flattened stems) appressed to the trunks of trees, including 


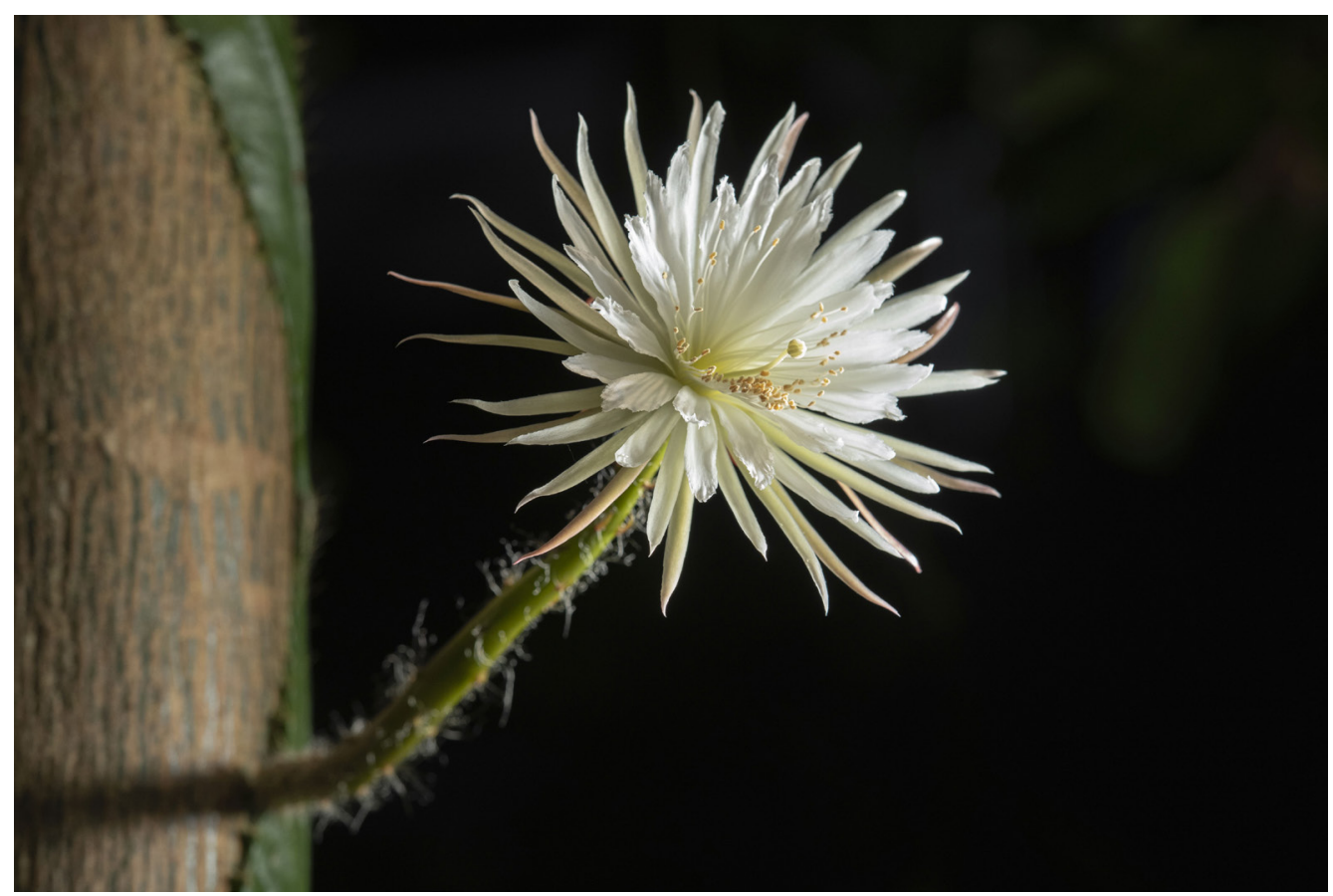

Fig. 3 Strophocactus wittii in flower. Photo: Howard Rice.

the Pachira aquatica that hosts it in our tropical glasshouse. Our specimen was donated by Bonn Botanic Garden in 2015, and was the first example of this species flowering in the UK. While the flower is attractive and unusual, we were entirely unprepared for the level of interest it would generate from a world made miserable by successive lockdowns and from people keen to imagine themselves exploring the plants of far-off places. We used a webcam to film the opening of the floral bud, and this attracted over 400,000 views from all over the world. Activity on our Twitter, Facebook and Instagram feeds surged as people looked for updates and commented on the webcam action. And on the night the flower opened, a Facebook Live from a ladder next to the flower was watched by 617 people who fired enthusiastic questions at Alex Summers, our Glasshouse Supervisor, who talked about the horticulture, and myself, as Director of CUBG and a plant scientist talking about the floral structure and its pollination. As with the Wellness Wanders, it was clear that people were most keen to feel the connection to the plant, with questions about its smell, how it felt, the texture of the petals and the whole experience of watching the flower open in real time. It was obvious from the torrent of enthusiasm for this one flowering event that the global appetite for botanical knowledge, thoughtfully presented to allow true engagement, was not going to be short-lived and could not be met by simply returning to a focus on in-person visitors to the garden.

\section{The success of online botanic gardens: wider audiences, deeper engagement}

Our experience at CUBG was by no means unique. Colleagues at other botanic gardens 
around the world reported increased visits to their websites, greater enthusiasm for their digital offerings and a substantial level of engagement with online course provision (Castleberry, 2020). This new style of engagement brings three sets of benefits over our traditional in-person offering:

1. The potential for a geographically broader audience. Inevitably, focusing on physical visitors limits a botanic garden's reach to those who live within a few hours' journey time and to those who are visiting an area for business or tourism. But an online audience can be global. We have had engagement with our digital events from people in North America, South America, Africa, Asia and Australia, as well as across Europe. Pre-recorded events or outputs allow people to engage whatever time zone they are in, although live events can generate a more genuinely interactive and connected feel.

2. The potential for a socially broader audience. Visitors to botanic gardens often fall into a few traditional groups - young families looking for a safe, semi-natural environment, older people who enjoy gardening and horticulture, well-educated people interested in learning more about plant science and nature. But an online presence can be targeted to reach different groups, and the very nature of the digital platforms used can be adapted to appeal to different age ranges. It is traditionally difficult to capture the interest of older teenagers, for instance, but use of the right social media platforms (not Facebook, which appeals to an older audience, but Instagram and other visual platforms) can generate appeal, particularly if paired with socially relevant content.

3. The potential for a true depth of engagement that is hard to achieve in person. This may seem to contradict the traditional focus of botanic gardens on physical connection between plant and person. However, detailed analysis of botanic garden visitors reveals that many do not engage with any depth, taking only a superficial interest in the plants that they see. An online engagement is, by its very nature, more targeted. The audience is immersed in the content that is shared, and, if it is thoughtfully designed with a focus on who the audience is, will leave with a far greater depth of understanding and feeling of connectedness than can be achieved by a passive visit to a physical garden. This, for me, was the truly astonishing discovery that came from the flowering of our moonflower. Had our glasshouses been open to the public in February 2021, a few thousand people, at most, would have walked past it and had a look (for comparison, 3,500 visited our most recent flowering Amorphophallus titanum). ${ }^{4} \mathrm{~A}$ few hundred might have stopped and fully engaged, and even fewer would have read the interpretative material we would have provided. But several hundred thousand people chose to connect online and to hear the stories, share discussions and absorb the beauty of the flower. They were not just more in number and distribution, they were also engaging consciously and actively, and so potentially with a greater depth than we have seen before.

${ }^{4}$ See www.botanic.cam.ac.uk/titus-arum-titanic-success/ 


\section{The challenge for the future: balancing physical and digital connections}

In late 2021 the Covid-19 pandemic looks set to continue to limit activity for some time to come, with vulnerable people reluctant to travel and to visit busy sites, including, possibly, botanic gardens. This in itself argues for a continued digital presence for our living collections, and for further efforts to engage audiences online with the beauty and wonder of plants. However, my purpose in writing this Guest Essay was to argue for something much more positive than this - not just a continued online presence in response to Covid-19, but a concerted effort by the botanic garden community to develop strategies for digital engagement that will stretch into the future. Our collective experiences of the power of online engagement to grow audiences, broaden them geographically and socially, and connect them more deeply to the plants we curate should form the springboard for a new balanced model of engagement where we share our collections physically and at the same time produce targeted, thoughtful, imaginative online content that has the power to build true depth of connection. We have shown over the last decades that we can connect people and plants physically. We have shown over the last two years that we can generate remarkable connections digitally, when circumstances force our hand. The challenge now is to bring these elements together and to use what we have learned to give our amazing plants the voice and the reach they deserve, now and for the future.

\section{References}

\section{ASSOCIATION OF LEADING VISITOR}

ATTRACTIONS (N.D.). Available online: www.alva. org.uk/details.cfm? $\mathrm{p}=615$ (accessed December 2021).

CARRUS, G., SCOPELLITI, M., PANNO, A., LAFORTEZZA, R., COLANGELO, G., PIRCHIO, S., FERRINI, F., SALBITANO, F., AGRIMI, M., PORTOGHESI, L., SEMENZATO, P. \& SANESI, G. (2017). A different way to stay in touch with 'urban nature': the perceived restorative qualities of botanical gardens. Frontiers in Psychology, 8: 914. doi: https://doi.org/10.3389/fpsyg.2017.00914

CASTLEBERRY, K. (2020). The impact of Covid-19 on botanic gardens globally. BGJournal, 17(2): 7-8. Available online: www.bgci.org/news-events/ the-impact-of-covid-19-on-botanic-gardensglobally (accessed December 2021).

CHEN, G. \& SUN, W. (2018). The role of botanical gardens in scientific research, conservation, and citizen science. Plant Diversity, 40: 181-188. doi: https://doi.org/10.1016/j.pld.2018.07.006 MOUNCE, R., SMITH, P. \& BROCKINGTON, S. (2017). Ex situ conservation of plant diversity in the world's botanic gardens. Nature Plants, 3: 795-802. doi: https://doi.org/10.1038/s41477-017-0019-3 